\title{
Urticaria as a Manifestation of Hyperthyroidism
}

\author{
Nicholas Womack ${ }^{1}$ and Edward Jude ${ }^{1}$ \\ ${ }^{1}$ Tameside and Glossop IC NHS FT
}

June 2, 2020

\begin{abstract}
Objective: To review a case of acute urticaria, and to explore the links this presentation shares with hyperthyroidism and anti-thyroid medications, along with management strategies for patients presenting with new-onset urticaria and pre-existing thyroid disease. Design: A retrospective case report on a 23-year-old female with hyperthyroidism, on carbimazole therapy.

Urticaria as a Manifestation of Hyperthyroidism

Dr Nicholas Womack

Prof Edward Jude

Tameside and Glossop Integrated Care NHS Foundation Trust

Address all correspondence, proofs and requests for reprints to: Dr Nicholas Womack, Tameside and Glossop Integrated Care NHS Foundation Trust, Ashton-Under-Lyne, OL6 9RW, UK.

E-mail: nwomack@doctors.org.uk

Conflict of interests: The authors have no conflicts of interest to declare

Word count: 1252 (excluding references and abstract)
\end{abstract}

\section{Key words}

Urticaria, hyperthyroidism, carbimazole.

\section{Key clinical message}

In clinically euthyroid patients presenting with urticaria, a trial period of withholding anti-thyroid medications can be exercised.

In clinically hyperthyroid patients, anti-thyroid medications may be stopped with close observation of response.

\section{Summary}

Urticaria is a common, pruritic skin condition with multiple causes and can have a significant impact on quality of life. In this paper we present a case of acute urticaria secondary to hyperthyroidism. This link appears to be due to the autoimmune thyroid cascade (particularly IgE anti-thyroid peroxidase (TPO) antibodies) sensitising mast cells for activation and histamine release. Although anti-histamines and steroids are first-line treatment, identifying the "causative" factor is not easy in hyperthyroid patients due to the independent links urticaria shares with both carbimazole and thyrotoxicosis.

\section{Background}


Urticaria consists of blanchable, erythematous "wheals" secondary to vasoactive mediators, predominantly histamine release from mast cells. Wheals are usually transient, disappearing from one aspect of the body and reappearing in new areas, and almost always pruritic. Acute urticaria refers to a presentation of less than six weeks, otherwise the term chronic urticaria is used. Most cases are idiopathic, but known triggers include drugs, infections, foods and even certain physical factors (such as cold, heat and sunlight) ${ }^{1}$.

Hyperthyroidism results from an excess state of thyroid hormones caused by excess release and increased synthesis from the thyroid gland, or less commonly, from extrathyroidal sources. Excess thyroid release is often stimulated by specific antibodies, including anti-thyroid peroxidase (TPO), anti-thyroglobulin (Tg), and anti-thyroid-stimulating hormone receptor (TSHR) antibodies ${ }^{2}$. Graves' disease, the most common cause of hyperthyroidism, is an example of an autoimmune disease where thyroid-stimulating antibodies activate thyroid-stimulating hormone receptors, leading to excess hormone release from the thyroid gland ${ }^{3}$.

Urticaria and autoimmune hyperthyroidism appear to share an aetiological relationship, although the exact mechanism remains ambiguous ${ }^{4}$. In this report we discuss a new case of urticaria presenting itself as a manifestation of hyperthyroidism, the pathophysiology to this link is explored and management strategies are discussed.

\section{Case Presentation}

A 23-year-old female with a recent diagnosis of hyperthyroidism presented to her GP with an urticarial rash localised to her neck. She was prescribed a course of cetirizine and prednisolone. Shortly after, she presented to the emergency department with a spreading urticarial rash extending to her neck, stomach, chest, back, genitals, upper and lower legs, consisting of "extensive excoriations and dermatographia, with blanching and wheals" (figures $18 \% 2$ ). She had given birth to her first child as recently as four months ago and the only other medication she took on a regular basis was carbimazole, which was started one month prior to her presentation.

Investigations revealed normal inflammatory markers (CRP $2 \mathrm{mg} / L$, WBC $9.3 \times 10^{9} / L$ ) and her renal \& liver function tests all remained within normal limits. No clinical findings were evident on examination of her chest and abdomen and no focal neurology was elicited. Her FT4 two weeks prior to admission was $38.4 \mathrm{pmol} / \mathrm{l}$, with a TSH of $0.01 \mathrm{mU} / \mathrm{l}$, although her FT4 on the day of admission was normal at 10.7 $\mathrm{pmol} / \mathrm{l}$. She was treated with intravenous chlorphenamine in the emergency department then admitted for observation and referred to the endocrinologist.

Over the next 48 hours she had a further exacerbation of her rash which now resulted in lip swelling and she was started on intravenous hydrocortisone and oral loratadine. Her carbimazole was stopped due to concerns it may be the cause of the rash. She was reviewed the next day and an urgent dermatology opinion was sought, whilst a full autoimmune screen was sent (all negative, see table 1). Urinalysis was also negative. Thyroid peroxidase antibody (anti-TPO) levels were raised at $>1000 \mathrm{iU} / \mathrm{mL}$.

After dermatology review the patient was started on oral chlorphenamine (at triple the normal licensed dose), topical menthol $1 \%$ cream and her steroid dose was gradually reduced. After five days of treatment her urticaria was limited to her legs and scalp, and she had symptomatically improved.

\section{Outcome and follow-up}

Once the patient's symptoms had improved, she was discharged having stayed in hospital for a total of one week. She had an ultrasound of her thyroid two weeks after discharge which showed diffuse thyroiditis along with a right U2 thyroid nodule. She is being followed up in both endocrine and dermatology clinics.

\section{Discussion}

The lifetime prevalence of acute urticaria is estimated to be $15-23 \%$ in adults and up to $14.5 \%$ in children ${ }^{5}$. The detriment to quality of life is severe, and applicable to social, recreational, vocational and emotional aspects of life $\mathrm{e}^{6,7}$. Management consists of high dose anti-histamines along with steroid use and avoidance of causative factors ${ }^{8}$. 
In rare circumstances, urticaria can be the presenting feature of hyperthyroidism. Rothfield ${ }^{9}$ reviewed 108 cases of hyperthyroidism and found 2 cases of urticaria (1.85\%) that varied with the degree of hyperthyroidism. Pruritis was also found in a number of patients, and severity varied along with thyroid state in 5 out of the 108 cases (4.63\%).

The mechanism linking urticaria and hyperthyroidism is not clearly understood. Chronic urticaria is thought to be triggered by activation and degranulation of mast cells. Although IgG anti-thyroid auto-antibodies do not directly activate mast cells, they are postulated to make them more susceptible to activation by other mediators ${ }^{10}$. In this case, thyroid peroxidase antibodies were $>1000 \mathrm{iU} / \mathrm{mL}$. Another proposed theory is that $\operatorname{IgE}$ anti-TPO antibodies directly bind to mast cells to cause autoallergic mast cell degranulation and activation ${ }^{11}$. Furthermore, omalizumab, an anti-IgE therapy, provides particularly good symptomatic improvement in patients with urticaria and positive $\operatorname{IgE}$ anti-TPO antibodies ${ }^{12}$.

Treatment for hyperthyroidism consists of medications, surgery or radioiodine. The currently licensed medications for hyperthyroidism include carbimazole (converted to methimazole) and propylthiouracil, both of which reduce the conversion of thyroxine (T4) to its active form, triiodothyronine (T3) ${ }^{13,14}$. Specifically, methimazole and propylthiouracil impede iodination of tyrosine residues in thyroglobulin, an important step in conversion of T4 to T3. Propylthiouracil also inhibits peripheral conversion of T4 to T3, although the therapeutic effect of this is unclear ${ }^{13}$.

Carbimazole itself is also a known cause of rash and urticaria ${ }^{15,16}$. A review of the yellow card scheme between 1981 to 2003 found rashes to be the $4^{\text {th }}$ most common side effect for carbimazole, behind neutropenia, hepatobiliary disorders and agranulocytosis ${ }^{17}$. Propylthiouracil, the lesser used medication for hyperthyroidism, has a number of adverse effects including urticaria and other skin reactions; skin eruptions occur in $4-6 \%$ of patients ${ }^{18}$.

In patients that are otherwise clinically euthyroid, a suitable strategy would be to withhold carbimazole (or propylthiouracil) when an urticarial rash first develops. But the correct action in patients with uncontrolled hyperthyroidism is less clear, as withholding anti-thyroid drugs could result in an exacerbation of thyrotoxicosis and consequently intensify the urticaria. In such patients, a trial period of carbimazole-free therapy in order to closely assess urticarial response would be justified. Talaprapta et al ${ }^{19}$ faced the above dilemma in 2007, and opted to withhold carbimazole therapy, resulting in an aggravated thyrotoxicosis with a persistent rash. They then found the urticarial rash to improve once the patient's hyperthyroid state had resolved with propylthiouracil.

In our patient the hyperthyroidism developed shortly before urticaria, although she was clinically euthyroid when she presented to hospital. But despite the unremarkable FT4 level, it is likely that the IgE anti-TPO cascade was still rampant as evidenced by the high anti-TPO levels. Interestingly, the decision to stop carbimazole did result in symptomatic relief however this coincided with high dose anti-histamines.

In such patients where the true cause of urticaria is unclear symptomatic relief can be sought while investigating with a trial-and-error approach (see table 2) .

Consent: Written and verbal consent provided by patient for the article and related images

Competing interests: None

Data Sharing: The data that support the findings of this study are openly available in [repository name e.g "figshare"] at http://doi.org/[doi], reference number [reference number].

\section{Author contributions}

$N$ Womack: Conception/analysis, drafting of the article, critical revision of the article, final approval.

E Jude: Conception/analysis, critical revision of the article, final approval.

\section{References}


1) Deacock, S. (2008). An approach to the patient with urticaria. Clinical \& Experimental Immunology, 153(2), pp.151-161.

2) Fröhlich, E. and Wahl, R. (2017). Thyroid Autoimmunity: Role of Anti-thyroid Antibodies in Thyroid and Extra-Thyroidal Diseases. Frontiers in Immunology, 8.

3) Kravets, I. (2016). Hyperthyroidism: Diagnosis and Treatment. American Family Physician, 93(5), pp.1-2.

4) Isaacs, N. and Ertel, N. (1971). Urticaria and pruritus: Uncommon manifestations of hyperthyroidism. Journal of Allergy and Clinical Immunology, 48(2), pp.73-81.

5) Lee, S., Ha, E., Jee, H., Lee, K., Lee, S., Kim, M., Kim, D., Jung, Y., Sheen, Y., Sung, M. and Han, M. (2017). Prevalence and Risk Factors of Urticaria With a Focus on Chronic Urticaria in Children. Allergy, Asthma \& Immunology Research, 9(3), p.212.

6) O'Donnell, B., Lawlor, F., Simpson, J., Morgan, M. and Greaves, M. (1997). The impact of chronic urticaria on the quality of life. British Journal of Dermatology, 136(2), pp.197-201.

7) Baiardini, I., Pasquali, M., Braido, F., Fumagalli, F., Guerra, L., Compalati, E., Braga, M., Lombardi, C., Fassio, O. and Canonica, G. (2005). A new tool to evaluate the impact of chronic urticaria on quality of life: chronic urticaria quality of life questionnaire (CU-Q2oL). Allergy, 60(8), pp.1073-1078.

8) Cks.nice.org.uk. (2019). Urticaria - NICE CKS. [online] Available at: https://cks.nice.org.uk/urticaria\#!scenario [Accessed 20 Jul. 2019].

9) Rothfeld, B. (1968). Pruritus as a Symptom in Hyperthyroidism. JAMA: The Journal of the American Medical Association, 205(1), p.52.

10) Selvendran, S. and Aggarwal, N. (2018). Chronic urticaria and thyroid autoimmunity: a perplexing association. Oxford Medical Case Reports, 2018(2).

11) Altrichter, S., Peter, H., Pisarevskaja, D., Metz, M., Martus, P. and Maurer, M. (2011). IgE Mediated Autoallergy against Thyroid Peroxidase - A Novel Pathomechanism of Chronic Spontaneous Urticaria?. PLoS ONE, 6(4), p.e14794.

12) Metz, M., Staubach, P., Bauer, A., Brehler, R., Gericke, J., Kangas, M., Ashton-Chess, J., Jarvis, P., Georgiou, P., Canvin, J., Hillenbrand, R., Erpenbeck, V. and Maurer, M. (2017). Clinical efficacy of omalizumab in chronic spontaneous urticaria is associated with a reduction of FceRI-positive cells in the skin. Theranostics, 7(5), pp.1266-1276.

13) Abraham, P. and Acharya (2009). Current and emerging treatment options for Graves' hyperthyroidism. Therapeutics and Clinical Risk Management, p.29.

14) Brent, G. (2012). Mechanisms of thyroid hormone action. Journal of Clinical Investigation, 122(9), pp.3035-3043.

15) Ponmani, C., Mcclatchey, M., Kanzaria, S., Keane, M. and Banerjee, K. (2014). Severe Urticaria in Graves' Disease: is Carbimazole to Blame?. Hormone Research in Paediatrics, [online] 82(P-D-2-2-599). Available at: http://abstracts.eurospe.org/hrp/0082/hrp0082p2-d2-599 [Accessed 20 Jul. 2019].

16) Pan, S., Wood, D. and Chatterjee, K. (2012). Fixed drug eruption in the endocrine clinic: rare presentation of reaction to carbimazole. Endocrine Abstracts, [online] 28(P367). Available at: https://www.endocrine-abstracts.org/ea/0028/ea0028p367 [Accessed 20 Jul. 2019].

17) Pearce, S. (2004). Spontaneous reporting of adverse reactions to carbimazole and propylthiouracil in the UK. Clinical Endocrinology, 61(5), pp.589-594.

18) Demir, M., Yaylaci, S., Tamer, A. and Ayturk, S. (2013). Propylthiouracil induced leukocytoclastic vasculitis: A rare manifestation. Indian Journal of Endocrinology and Metabolism, 17(2), p.339. 
19) Talapatra, I., Prabhakar, K. and Tymms, D. (2007). Urticaria; An Uncommon Presentation Of Thyrotoxicosis. European Journal of General Medicine, 4(4), pp.205-208.

\section{Figure legends}

Figure 1: Patient presented with acute urticaria

Figure 2: Patient presented with acute urticaria

Table 1: Autoimmune screening tests

Tablet 2: Summary of recommendations

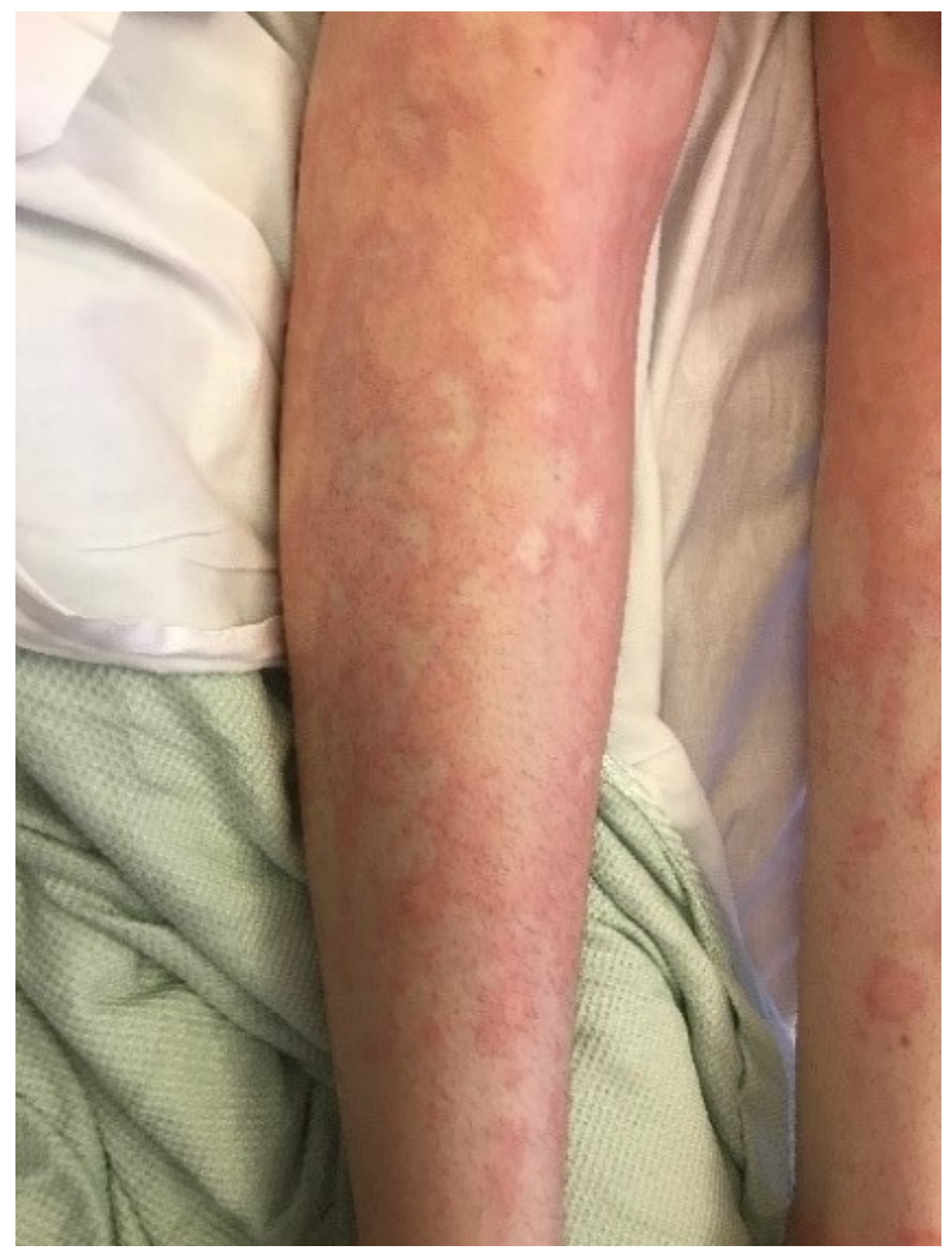




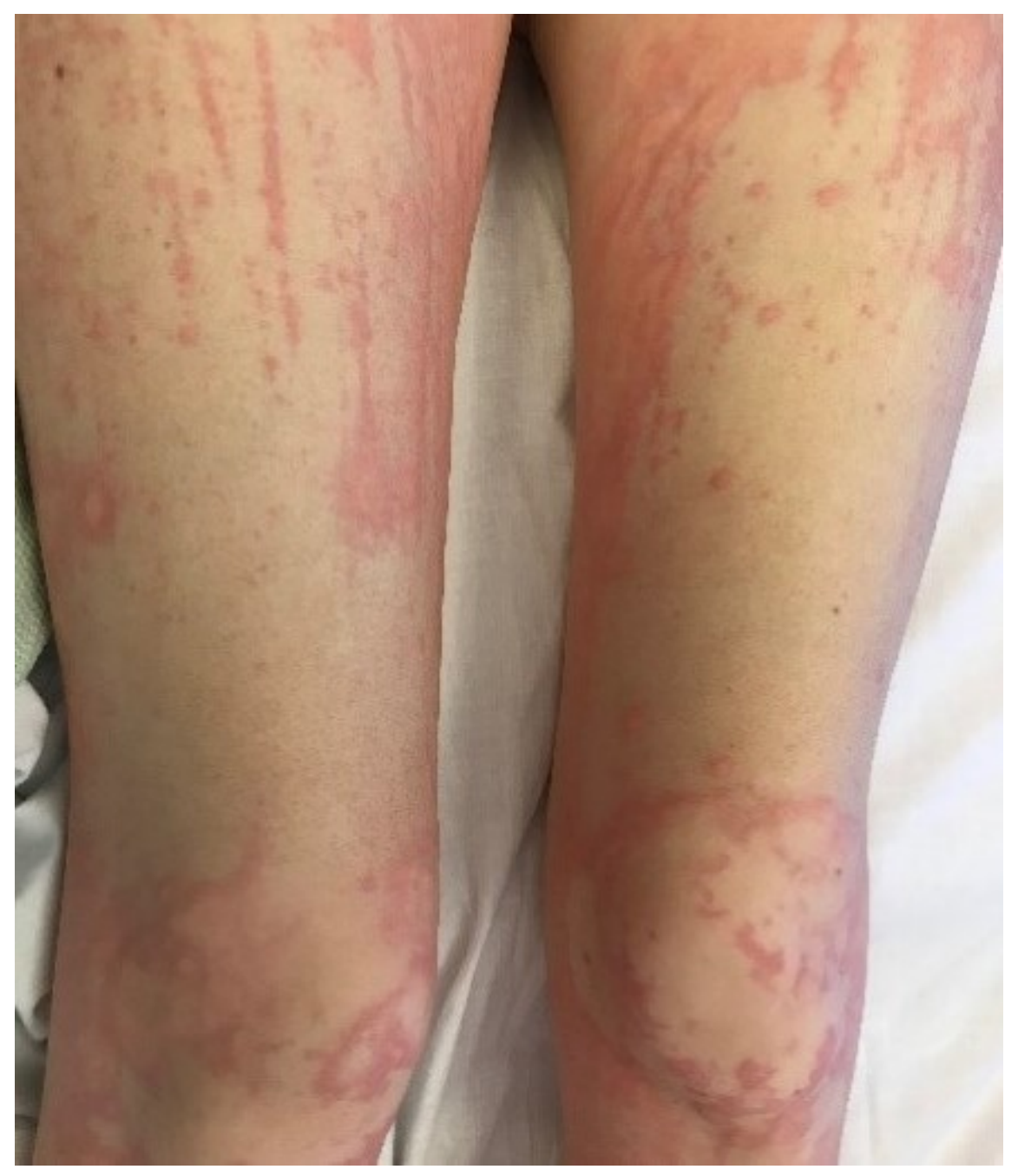

